\title{
Simultaneous analysis of rotational and vibrational-rotational spectra of DF and HF to obtain irreducible molecular constants for $\mathbf{H F}$
}

\author{
Koui Horiai and Hiromichi Uehara* \\ Department of Chemistry, Faculty of Science, Josai University, Keyakidai, Sakado, \\ Saitama 350-0295, Japan.
}

* Corresponding author. Tel.: +81 492717291; fax: +81 492717985.

E-mail address: huehara@josai.ac.jp (H. Uehara) 


\begin{abstract}
Analytic expressions of corrections for the breakdown of the Born-Oppenheimer approximation to Dunham's $Y_{i j}$ with optimal parameters, i.e., determinable clusters of expansion coefficients, are applied to a data analysis of the rotational and vibrational-rotational transitions of HF reported in the literature. All the available spectral lines of the two isotopologues, DF and HF, are simultaneously fitted to a single set of molecular parameters of HF within experimental errors. Fitting of a data set of 595 spectral transitions for DF and HF has generated only 20 minimal independent parameter values, i.e., "irreducible" molecular constants of HF, that are sufficient to precisely generate $82 Y_{i j}$ coefficients and 144 band constants in total: $41 Y_{i j}$ and 72 band constants each for DF and HF.
\end{abstract}

Key words: Born-Oppenheimer, breakdown, DF, HF 


\section{Introduction}

A series of rotational transitions of $\mathrm{HF}$ from $J=1-0$ up to $J=33-32$ that are interspersed in the far-infrared and mid-infrared ranges up to $1100 \mathrm{~cm}^{-1}[1-5]$ are useful calibration standards for spectral lines of molecules measured at high temperature. In a previous study [6], we re-measured the important rotational transitions with a Fourier transform spectrometer (FTS) with slightly higher resolution than those in earlier studies [2, 3] and confirmed the reported accuracy, $\pm 0.0002 \mathrm{~cm}^{-1}$ [2], associated with the spectral lines in the range from 600 to $1000 \mathrm{~cm}^{-1}$. The reported rotational and vibrational-rotational transitions $[3,7,8]$ for several vibrational levels plus our rotational measurements for a single isotopologue of HF have been analyzed simultaneously by an analytical approach with a non-Born-Oppenheimer effective Hamiltonian [6]. This analysis is the first non-Born-Oppenheimer analysis of a single isotopologue with physically meaningful parameters based on the traditional concept of the molecular constants.

A set of rotational and vibrational-rotational spectral data of diatomic molecules has usually been analyzed by a simultaneous fitting of a single set of molecular parameters to the multiple vibrational bands of various isotopologues, if any. Typically, energy levels expressed by

$$
E_{v J} / h c=\sum_{i, j} \mu^{-(i+2 j) / 2} U_{i j}\left[1+\left(m_{\mathrm{e}} / M_{a}\right) \Delta_{i j}^{a}+\left(m_{\mathrm{e}} / M_{b}\right) \Delta_{i j}^{b}\right](v+1 / 2)^{i}[J(J+1)]^{j}
$$

are used for the fitting, where $U_{i j}$ and $\Delta_{i j}$ are mass-invariant constants [9-11]. Although an analysis with equation 1 is conventional [12], the empirical parameters $\Delta_{i j}$ introduced for corrections of the breakdown of the Born-Oppenheimer approximation have redundancies [13].

The present method for determining non-Born-Oppenheimer parameters is the analytical approach which proposes a certain set of combinations of the individual expansion coefficients of the non-Born-Oppenheimer correction functions $[9,10,14-16]$ for the adiabatic and nonadiabatic vibrational and rotational effects as the determinable quantities [13, 17].

Theoretical studies of potential-fit analyses [18] of HF and DF [19-21] have been conducted. In a recent study of Coxon and Hajigeorgiou [21], the Hamiltonian is defined for a particular 
isotopologue $i$ on the basis of the theoretical work by Watson [10]. The numerical approach in Ref. [21], which utilizes an analytical potential model with an iterative direct potential-fit method, works well to reproduce spectral data over a large internuclear distance, but it differs from our analytical approach both in the approach and the goal. They introduced an overall analytical potential-function ignoring the traditional concept of molecular constants. Watson's Hamiltonian [10] aims at separate determination of the isotopically invariant $\mu B_{\mathrm{e}}\left(=U_{01}\right), \mu^{1 / 2} \omega_{\mathrm{e}}\left(=U_{10}\right)$, Dunham's potential constant $a_{k}$ (the Born-Oppenheimer potential), and two functions $\widetilde{R}_{a, b}(\xi)$ and $\widetilde{S}_{a, b}(\xi)$ by a simultaneous fitting of the spectral lines of multiple isotopologues. In our study of the analytical approach [13], we have converted the original fitting parameters to those determinable by fitting to the transitions of a single isotopologue based on the generally accepted concept of the molecular constants that correspond to the Dunham series expansion [22].

Many studies have been reported on the high-resolution rotational and vibrational-rotational spectra of DF. Helminger et al. [23] and De Lucia et al. [24] observed a $J=1-0$ rotational spectrum with a submillimeter-wave spectrometer. Spanbauer et al. [25] observed the vibrational-rotational $v=$ 1-0 and 2-1 bands with an accuracy of $c a .0 .01 \mathrm{~cm}^{-1}$. Sengupta et al. [26] reported $42 P$-branch lines in the vibrational-rotational laser transitions in the $v=1-0$ to 4-3 bands with an accuracy of \pm 0.003 $\mathrm{cm}^{-1}$. A comprehensive measurement of the DF spectrum has been made by Ram et al. [3], who reported the rotational and the vibrational-rotational spectra of up to $J^{\prime \prime}=34$ and $v=5-4$ band, respectively, observed at $2670 \mathrm{~K}$ using an FTS. Recently, two benchmark measurements of the rotational transitions have been made: Cazzoli and Puzzarini [27] observed a Lamb-dip spectrum of the $J=1-0$ transition with a microwave spectrometer, while Cazzoli et al. [28] measured the rotational transitions from $J=2-1$ to 5-4 using a tunable far-infrared (TuFIR) spectrometer.

A data set of the reported high-resolution rotational and vibrational-rotational spectra for a single isotopologue HF [1-8] has previously been analyzed using a non-Born-Oppenheimer Hamiltonian [6], which yielded values of physically meaningful molecular parameters for any combination of isotopologues; choices of the fitting parameters for the case of a single isotopogue HF and that of two isotopologues DF and HF have been reported in Ref. [6] and in the present study, respectively. 
In the present paper, we report a result of a simultaneous analysis of the high-resolution spectra of DF and HF as an extension of our previous study of HF [6]. A spectral data set of DF and HF has been analyzed simultaneously with the fitting parameters of $U_{\omega}\left(1+m_{\mathrm{e}} \Delta_{\omega}{ }^{\mathrm{F}} / M_{\mathrm{F}}\right), U_{B}\left(1+m_{\mathrm{e}} \Delta_{B}{ }^{\mathrm{F}} / M_{\mathrm{F}}\right)$,

$a_{i}\left(1+m_{\mathrm{e}} \Delta_{a i q}{ }^{\mathrm{F}} / M_{\mathrm{F}}\right)(i=1,2, \ldots), \Delta_{\omega}{ }^{\mathrm{H}}, \Delta_{B}{ }^{\mathrm{H}}, \Delta_{a i q}{ }^{\mathrm{H}}(i=1,2, \ldots)$, and $r_{i q}{ }^{\mathrm{H}}\left(=r_{i q}{ }^{\mathrm{F}}\right)(i=1,2, \ldots)$, that are based on the traditional concept of molecular constants; note that they are irreducible molecular parameters for $\mathrm{HF}$, because ${ }^{19} \mathrm{~F}$ is a single nuclide. The individual non-Born-Oppenheimer parameters defined in Refs. $[6,13]$ are summarized in Table 1.

\section{Method of Analysis}

The method of analysis has been reviewed in Ref. [6] but is reproduced briefly. An original non-Born-Oppenheimer effective Hamiltonian $[10,15,16,29,30]$ in the electronic state ${ }^{1} \Sigma$, where terms higher than $\mathrm{O}\left(m_{\mathrm{e}} / M_{a, b}\right)$ are ignored, yields a Schrödinger equation in terms of the variable $\xi=\left(r-r_{\mathrm{e}}\right) / r_{\mathrm{e}}$ as $[13]$

$$
\begin{aligned}
& {\left[-\frac{h^{2}}{8 \pi^{2} \mu r_{\mathrm{e}}^{2}} \frac{\mathrm{d}}{\mathrm{d} \xi}\left\{1+\left(m_{\mathrm{e}} / M_{a}\right) Q_{a}(\xi)+\left(m_{\mathrm{e}} / M_{b}\right) Q_{b}(\xi)\right\} \frac{\mathrm{d}}{\mathrm{d} \xi}\right.} \\
& \quad+\frac{h^{2}}{8 \pi^{2} \mu r_{\mathrm{e}}^{2}(1+\xi)^{2}}\left\{1+\left(m_{\mathrm{e}} / M_{a}\right) R_{a}(\xi)+\left(m_{\mathrm{e}} / M_{b}\right) R_{b}(\xi)\right\} J(J+1) \\
& \left.\quad+V(\xi)+\left(m_{\mathrm{e}} / M_{a}\right) S_{a}(\xi)+\left(m_{\mathrm{e}} / M_{b}\right) S_{b}(\xi)\right] \psi_{v J}(\xi)=E_{v J} \psi_{v J}(\xi),
\end{aligned}
$$

where $\mu$ is the reduced mass of a molecule and $M_{a}, M_{b}$, and $m_{\mathrm{e}}$ are the masses of atoms $\mathrm{A}, \mathrm{B}$ and the electron, respectively. The equilibrium internuclear distance $r_{\mathrm{e}}$, that is the minimum of Dunham's potential function $V(\xi)$ [31] at $\xi=0$, is isotopically invariant. Mass-independent functions, e.g., after Watson [10], $Q_{a, b}(\xi), R_{a, b}(\xi)$, and $S_{a, b}(\xi)$ are the non-Born-Oppenheimer terms for nonadiabatic vibrational, nonadiabatic rotational, and adiabatic effects, respectively. 
The functions $Q_{a, b}(\xi), R_{a, b}(\xi)$, and $S_{a, b}(\xi)$ are expressed as a series expansion in $\xi$; similar to Dunham's potential function [31], as

$$
V(\xi)=(1 / 2) k r_{\mathrm{e}}^{2} \xi^{2}\left(1+a_{1} \xi+a_{2} \xi^{2}+\ldots\right),
$$

in which the force constant $k$ and the potential constants, $a_{1}, a_{2}, \ldots$, are isotopically invariant, and the expansion coefficients of the $\xi^{i}$ terms of $Q_{a, b}(\xi), R_{a, b}(\xi)$, and $S_{a, b}(\xi)$ are $q_{i}^{a, b}, r_{i}^{a, b}$, and $s_{i}^{a, b}$, respectively [13]. The treatments described below are applicable to local representations near $r_{\mathrm{e}}$ in a region with $|\xi|<1$. An appropriate manipulation of the Hamiltonian in equation 2 has generated an effective non-Born-Oppenheimer Hamiltonian expressed using a set of optimal parameters as [32]

$$
\begin{aligned}
H=-B_{\mathrm{e}}(1+ & \left.\delta \Delta_{B}\right) \frac{d^{2}}{d \xi^{\prime 2}}+\frac{B_{\mathrm{e}}\left(1+\delta \Delta_{B}\right)}{\left(1+\xi^{\prime}\right)^{2}}\left(1+\sum_{i=1} \delta r_{i q}\left(\xi^{\prime}\right)^{i}\right) J(J+1) \\
& +\frac{\left[\omega_{\mathrm{e}}\left(1+\delta \Delta_{\omega}\right)\right]^{2}}{4 B_{\mathrm{e}}\left(1+\delta \Delta_{B}\right)} \xi^{\prime 2}\left(1+\sum_{i=1} a_{i}\left(1+\delta \Delta_{a i q}\right)\left(\xi^{\prime}\right)^{i}\right)
\end{aligned}
$$

where

$$
\begin{aligned}
\xi^{\prime} & =\left(1+\delta \Delta_{B} / 2\right) \xi+\delta \Delta_{B} / 2 \\
& =\left(1+\delta \Delta_{B} / 2\right) \frac{r-r_{\mathrm{e}}}{r_{\mathrm{e}}}+\delta \Delta_{B} / 2
\end{aligned}
$$

and $B_{\mathrm{e}}=h /\left(8 \pi^{2} c \mu r_{\mathrm{e}}^{2}\right)$ and $\omega_{\mathrm{e}}=(1 / 2 \pi c)(k / \mu)^{1 / 2}$ are in units of $\mathrm{cm}^{-1}$. These are the definition of $B_{\mathrm{e}}$ and $\omega_{\mathrm{e}}$. For a pair of the quantities $x_{i}^{a}$ and $x_{i}^{b}$, the symbol $\delta x_{i}$ denotes $\delta x_{i}=\left(m_{\mathrm{e}} / M_{a}\right) x_{i}^{\mathrm{a}}+\left(m_{\mathrm{e}} / M_{b}\right) x_{i}^{b}$ in which $x_{i}$ stands for an optimal correction parameter such as $\Delta_{B}, \Delta_{\omega}, r_{i q}$, or $\Delta_{a i q}, e . g ., \delta \Delta_{B}=\left(m_{\mathrm{e}} / M_{a}\right) \Delta_{B}{ }^{\mathrm{a}}+$ $\left(m_{\mathrm{e}} / M_{b}\right) \Delta_{B}{ }^{b}$. The quantities $x_{i}^{\mathrm{a}}$ and $x_{i}^{\mathrm{b}}$ are isotopically invariant. The optimal correction parameters are determinable clusters of the expansion coefficients $q_{i}^{a, b}, r_{i}^{a, b}$, and $s_{i}^{a, b}$ [13]. The correction parameters in terms of the expansion coefficients $q_{i}^{a, b}, r_{i}^{a, b}$, and $s_{i}^{a, b}$ are given in Refs. [6] and [13], but we list those equations in Table 2.

Equation 4 has formally the same form as that of the Dunham Hamiltonian [31] except for the corrections of the successive $\xi^{\prime i}$ terms of a series expansion of the rotational parameter $B\left(\xi^{\prime}\right)$. Note 
that the terms of orders higher than $\mathrm{O}\left(m_{\mathrm{e}} / M_{a, b}\right)$ should be ignored throughout. A Dunham-like treatment of the Schrödinger equation given in equation 4 yields the vibrational-rotational energy $F_{v J}$ in units of $\mathrm{cm}^{-1}$ that is identical to that of equation 2 as

$$
F_{v J}=\sum_{i j} Y_{i j}^{*}(v+1 / 2)^{i}[J(J+1)]^{j},
$$

where $Y_{i j}^{*}\left(=Y_{i j}{ }^{(0)}+Y_{i j}^{(2)}+\ldots\right)$ includes non-Born-Oppenheimer corrections to the Dunham coefficients. The $Y_{i j}{ }^{(0)}$ coefficients that are expressed with the correction parameters, $\delta \Delta_{B}, \delta \Delta_{\omega}, \delta \Delta_{a 1 q}$, $\delta \Delta_{a 2 q}, \delta \Delta_{a 3 q}, \delta r_{1 q}, \delta r_{2 q}, \delta r_{3 q}$, and $\delta r_{4 q}$, are given for the level set of eleven $Y_{i j}^{*(0)}[6]$, i.e., $\quad Y_{01} *^{(0)}, Y_{02}{ }^{(0)}$, $Y_{03}{ }^{(0)}, Y_{04}{ }^{(0)}, Y_{05}{ }^{(0)}, Y_{10} *^{(0)}, Y_{11}{ }^{(0)}, Y_{12}{ }^{(0)}, Y_{13} *^{(0)}, Y_{20} *^{(0)}$, and $Y_{21}{ }^{(0)}$ displayed in equations $36-43$ and equations 13 - 15 of Refs. [13] and [6], respectively. It is notable that the correction terms in $Y_{i j}{ }^{(0)}$ coefficients are the quantities of the order of $Y_{i j}^{(2)}$, i.e., the Dunham correction [31].

\section{Application to Spectral Data of DF and HF and Results}

The spectral data of DF in the electronic ground state ${ }^{1} \Sigma^{+}$were taken from the following papers: one Lamb-dip microwave spectrum of the $J=1-0$ transition given by Cazzoli and Puzzarini [27], four TuFIR rotational transitions from $J=2-1$ to 5-4 observed by Cazzoli et al. [28], 102 FTS rotational transitions of up to $v=3$ state, and 186 FTS vibrational-rotational transitions up to the $v=5-4$ band reported by Ram et al. [3] excluding one microwave transition. A compilation of the 302 spectral lines for HF in the electronic ground state ${ }^{1} \Sigma^{+}$is the same as those listed in Ref. [6] that consist of the transitions observed by Jennings et al. [1], Odashima et al. [4], Hedderich et al. [2], Ram et al. [3], Jennings and Wells [5], Le Blanc et al. [7], and Goddon et al. [8] plus the transitions measured by us [6].

The non-Born-Oppenheimer analysis with the Hamiltonian 4 yields values of physically meaningful molecular parameters for any combination of isotopologues. Because the $\mathrm{F}$ atom has only 
a single nuclide, isotopically invariant quantities $U_{\omega}, U_{B}, k, r_{\mathrm{e}}, a_{1}, a_{2}, \ldots$ cannot be evaluated from the simultaneous analysis of DF and HF; however the quantities invariant to the isotopic nuclide $\mathrm{H}$, i.e., the irreducible molecular parameters for HF, can be determined.

A total of 595 spectral lines composed of the 293 transitions of DF and 302 transitions of HF were simultaneously fitted with 20 irreducible molecular parameters: $U_{\omega}\left(1+m_{\mathrm{e}} \Delta_{\omega}{ }^{\mathrm{F}} / M_{\mathrm{F}}\right), U_{B}\left(1+m_{e} \Delta_{B}{ }^{\mathrm{F}} / M_{\mathrm{F}}\right)$, $a_{1}\left(1+m_{\mathrm{e}} \Delta_{a 1 q}{ }_{\mathrm{F}}^{\mathrm{F}} / M_{\mathrm{F}}\right), a_{2}\left(1+m_{\mathrm{e}} \Delta_{a 2 q}{ }_{\mathrm{F}} / M_{\mathrm{F}}\right), a_{3}\left(1+m_{\mathrm{e}} \Delta_{a 3 q}{ }_{\mathrm{F}} / M_{\mathrm{F}}\right), a_{4}, a_{5}, a_{6}, a_{7}, a_{8}, a_{9}, \Delta_{\omega}^{\mathrm{H}}, \Delta_{B}^{\mathrm{H}}, \Delta_{a 1 q}^{\mathrm{H}}, \Delta_{a 2 q}{ }^{\mathrm{H}}$, $\Delta_{a 3 q}{ }^{\mathrm{H}}, r_{1 q}{ }^{\mathrm{H}}\left(=r_{1 q}{ }^{\mathrm{F}}\right), r_{2 q}{ }^{\mathrm{H}}\left(=r_{2 q}{ }^{\mathrm{F}}\right), r_{3 q}{ }^{\mathrm{H}}\left(=r_{3 q}{ }^{\mathrm{F}}\right)$ and $r_{4 q}{ }^{\mathrm{H}}\left(=r_{4 q}{ }^{\mathrm{F}}\right)$, in which $U_{\omega}=\mu^{1 / 2} \omega_{\mathrm{e}}, U_{B}=\mu B_{\mathrm{e}}$ and the parameters $a_{i}(i=1,2, \ldots)$ are the Dunham potential constants.

An analysis has been made connecting these parameters with the vibrational-rotational energy levels through $Y_{i j}^{*(0)}+Y_{i j}^{(2)}$ and $Y_{i j}^{(0)}$. The level of correction of a set of eleven $Y_{i j}^{*(0)}$ [6] and the Dunham potential constants up to $a_{9}$ are found to be sufficient for the present analysis. A set of $41 Y_{i j}$ coefficients, for each of DF and HF, that connect the fitting parameters with the energy levels is given by $Y_{i j}^{*(0)}+Y_{i j}^{(2)}$ for $i j=01,02,03,04,05,10,11,12,13,20$, and 21 and $Y_{i j}^{(0)}$ for $i j=06,07,08,09,010$, $011,14,15,16,17,18,19,22,23,24,25,26,27,30,31,32,33,34,35,40,41,42,43,50$, and 51. References to the analytical expressions for those of $Y_{i j}^{*(0)}, Y_{i j}^{(2)}$, and $Y_{i j}^{(0)}$ including the potential constants of up to $a_{9}$ have been listed in Ref. [6]. The spectral uncertainties, $\delta_{\text {obs }}$, are those given in the reported papers from which the spectral data of DF and HF have been taken. The weights for the spectral fit of the data are assumed to be proportional to $\left(1 / \delta_{\mathrm{obs}}\right)^{2}$. The fundamental physical constants are taken from the 2006 CODATA recommended values [33]. The fit of a single data set consisting of the reported DF and HF transitions is satisfactory; the normalized standard deviation is 1.19 with 20 parameters. The transitions for the portion of the DF spectral data and the obs. - calc. values are presented as Table S1 in supplementary material to show the quality of the present analysis. The quality of the fit for the portion of the HF transitions is similar to that of the previous fit of only the HF data reported in Ref. [6]. The molecular parameters determined in the fit are given in Table 3.

To facilitate calculations or predictions of the spectral frequencies, the values of $41 Y_{i j}$ for each of DF and HF, which connect 20 molecular parameters with the energy values of DF and HF, have been back-calculated with the values of the parameters given in Table 3 . The values of $Y_{i j}$ in Table 3 are 
those of $Y_{i j}{ }^{*}$ given in equation 6; we use $Y_{i j}$ instead of $Y_{i j}{ }^{*}$ for convenience. A total of $82 Y_{i j}$ values for DF and HF are listed in Table 4.

\section{Discussion}

\subsection{Fitted molecular constants}

The physical significance of the non-Born-Oppenheimer potential function and the rotational energy is explained in equation 4. The irreducible molecular constants of HF, which is independent of the isotopic nuclide $\mathrm{H}$ or $\mathrm{D}$, have been evaluated for the first time as listed in Table 3 . From Table 3 the values of $r_{\mathrm{e}}\left(1-m_{\mathrm{e}} \Delta_{\mathrm{B}}^{\mathrm{F}} / 2 M_{\mathrm{F}}\right)=91.69834478(236) \mathrm{pm}$ and $k\left(1-2 m_{\mathrm{e}} \Delta_{\omega}^{\mathrm{F}} / M_{\mathrm{F}}\right)=965.667359(339) \mathrm{N} \mathrm{m}^{-1}$ are obtained, which are the irreducible values for $r_{\mathrm{e}}$ and $k$. The former value is significantly different from the $R_{\mathrm{e}}$ value of $91.683896(2) \mathrm{pm}$ estimated by Coxon and Hajigeorgiou [21] for HF by a simultaneous analysis of HF and DF data. They introduced an effective potential function $U_{\mathrm{HF}}{ }^{\text {eff }}(R)$ for $\mathrm{HF}$ and used $U^{\mathrm{H}}(R)$, which corresponds to $\widetilde{S}_{H}(R)$, to generate $U_{\mathrm{DF}}{ }^{\text {eff }}(R)$ from $U_{\mathrm{HF}}{ }^{\text {eff }}(R)$. Their value of $R_{\mathrm{e}}$ is the minimum of the effective potential function $U_{\mathrm{HF}}{ }^{\text {eff }}(R)$, which they precisely determined. Our approach indicates that the physical significance of the minimum of $U_{\mathrm{HF}}{ }^{\text {eff }}(R)$ is given by

$$
\begin{aligned}
r_{\mathrm{e}}\left(1-\delta \Delta_{B} / 2\right) & =r_{\mathrm{e}}\left(1-m_{\mathrm{e}} \Delta_{\mathrm{B}}{ }^{\mathrm{F}} / 2 M_{\mathrm{F}}-m_{\mathrm{e}} \Delta_{\mathrm{B}}{ }^{\mathrm{H}} / 2 M_{\mathrm{H}}\right) \\
& =r_{\mathrm{e}}\left(1-m_{\mathrm{e}} \Delta_{\mathrm{B}}{ }^{\mathrm{F}} / 2 M_{\mathrm{F}}\right)\left(1-m_{\mathrm{e}} \Delta_{\mathrm{B}}{ }^{\mathrm{H}} / 2 M_{\mathrm{H}}\right) .
\end{aligned}
$$

This $R_{\mathrm{e}}$ value is reducible. The value of $r_{\mathrm{e}}\left(1-\delta \Delta_{B} / 2\right)$ calculated from the values of the irreducible parameters $r_{\mathrm{e}}\left(1-m_{\mathrm{e}} \Delta_{\mathrm{B}}{ }^{\mathrm{F}} / 2 M_{\mathrm{F}}\right)$ and $\Delta_{\mathrm{B}}{ }^{\mathrm{H}}$ listed in Table $3,91.68389393(667) \mathrm{pm}$, agrees well with the $R_{\mathrm{e}}$ value of Coxon and Hajigeorgiou and also with our previous value of $r_{\mathrm{e}}\left(1-\delta \Delta_{B} / 2\right)=91.68389891(233)$ pm that has been obtained from the fitting of the HF data only within the error limits. The physical significance of $\delta \Delta_{B}$ is defined in terms of the expansion coefficients $r_{0}{ }^{\mathrm{H}, \mathrm{F}}$ and $s_{1}{ }^{\mathrm{H}, \mathrm{F}}$ of the correction functions $Q_{\mathrm{H}, \mathrm{F}}(\xi)$ and $S_{\mathrm{H}, \mathrm{F}}(\xi)$, respectively, and the relationships between $r_{0}{ }^{\mathrm{H}, \mathrm{F}}$ and the rotational $g$ factor and the electric dipole moment are given in equations 52 and 53 in Ref. [13]. The values of $\omega_{\mathrm{e}}$ $\left(1+m_{\mathrm{e}} \Delta_{\omega}^{\mathrm{F}} / M_{\mathrm{F}}\right)$ and $B_{\mathrm{e}}\left(1+m_{\mathrm{e}} \Delta_{B}^{\mathrm{F}} / M_{\mathrm{F}}\right)$ for DF and HF obtained from Table 3 are listed in Table $\mathrm{S} 2$ in 
Supplementary material.

We have shown that the non-Born-Oppenheimer correction parameters $\delta r_{i q}(i=1,2, \ldots)$ can be determined by an analysis of a single isotopologue [32]. Therefore, the same values of $r_{1 q}{ }^{\mathrm{H}}\left(=r_{1 q}{ }^{\mathrm{F}}\right)$, $r_{2 q}^{\mathrm{H}}\left(=r_{2 q}^{\mathrm{F}}\right), r_{3 q}^{\mathrm{H}}\left(=r_{3 q}{ }^{\mathrm{F}}\right)$, and $r_{4 q}^{\mathrm{H}}\left(=r_{4 q}^{\mathrm{F}}\right)$ should be obtained in all the cases of the simultaneous fit for $\mathrm{HF}$ and DF and the previous fit for a single isotopologue HF. Excellent agreement with the theory and the experimental results has been obtained because the values of $r_{1 q}{ }^{\mathrm{H}}\left(=r_{1 q}^{\mathrm{F}}\right)=-0.11113(357), r_{2 q}{ }^{\mathrm{H}}(=$ $\left.r_{2 q}{ }^{\mathrm{F}}\right)=-0.8322(494)$, and $r_{3 q}{ }^{\mathrm{H}}\left(=r_{3 q}{ }^{\mathrm{F}}\right)=0.4921(753)$ that have been determined in the previous fit [6] of the HF data alone agree with those given in Table 3 within the mutual error limits. The value of $r_{4 q}{ }^{\mathrm{H}}$ $\left(=r_{4 q}{ }^{\mathrm{F}}\right)=-0.557(385)$ [6] does not agree with the value listed in Table 3, but this deviation is acceptable because it carries large error limits and/or the truncation errors.

The above results provide evidence for the validity of the present scheme to determine the non-Born-Oppenheimer parameter $r_{i q}^{a}\left(=r_{i q}{ }^{b}\right)$ in an analysis of a single isotopologue for a molecule $\mathrm{AB}$ and the theoretical relation of $r_{i q}^{a}=r_{i q}{ }^{b}$. Our values of $r_{1 q}{ }^{\mathrm{H}}\left(=r_{1 q}{ }^{\mathrm{F}}\right)$ and $r_{2 q}{ }^{\mathrm{H}}\left(=r_{2 q}{ }^{\mathrm{F}}\right)$ are comparable with those of $q_{1}{ }^{\mathrm{H}}\left(=\widetilde{r}_{1}{ }^{\mathrm{H}}\right)=-0.111_{718}(3)$ and $q_{2}{ }^{\mathrm{H}}\left(=\widetilde{r}_{2}{ }^{\mathrm{H}}\right)=-0.71_{8557}(5)$ of Coxon and Hajigeorgiou [21], respectively. However, their values of $q_{1}{ }^{\mathrm{H}}, q_{2}{ }^{\mathrm{H}}$, and $q_{3}{ }^{\mathrm{H}}$ do not agree with those of $q_{1}{ }^{\mathrm{F}}, q_{2}{ }^{\mathrm{F}}$, and $q_{3}{ }^{\mathrm{F}}$, respectively [21], in conflict with the relation $r_{i q}{ }^{\mathrm{H}}\left(=\widetilde{r}_{i}^{\mathrm{H}}\right)={r_{i q}}^{\mathrm{F}}\left(=\widetilde{r}_{i}^{\mathrm{F}}\right)$ that has been found in Ref. [13] from equations 53 and 54. In both cases, $i=1$ under the symbol $\Sigma$ is a typing error and should read $i=0$. The discrepancy between the present study and Ref. [21] is left to be examined.

\subsection{Physical significance of the modified Dunham coefficients $Y_{i j}{ }^{*}$}

The modified Dunham coefficients $Y_{i j}{ }^{*}$, i.e., the Dunham coefficients that include the non-Born-Oppenheimer corrections are defined in equation 6. The values of $Y_{i j}^{*(0)}+Y_{i j}^{(2)}\left(=Y_{i j}^{*}\right)$ and $Y_{i j}^{(0)}$, which were back calculated from the 20 constants given in Table 3, are listed in Table 4 under the notation $Y_{i j}$. All $Y_{i j}$ values, except for $Y_{18}$ of DF and HF, are determined with smaller standard errors. In short, only 20 parameters are required in the present approach to fit the present set of spectral data with adjustable $Y_{i j}$, whereas $41 Y_{i j}$ parameters are required for each of DF and HF to reproduce the data.

A recent trend in spectral analyses is a dual treatment of independent fittings to the $Y_{i j}$ 
coefficients and to an overall potential function [34, 35]. In contrast, the present approach is a single fit to a potential function with only 20 fitting parameters; the analysis in the present approach has been made by using fewer fitting parameters compared to others.

The traditionally used effective molecular constants [22] such as $\omega_{\mathrm{e}},-\omega_{\mathrm{e}} x_{\mathrm{e}}, B_{\mathrm{e}},-\alpha_{\mathrm{e}}$, and $-D_{\mathrm{e}}$ correspond to the modified Dunham coefficients $Y_{10} *, Y_{20} *, Y_{01} *, Y_{11} *$, and $Y_{02} *$ [13], explicit expressions for which are reproduced in Supplementary material.

\subsection{Band constants}

The band constants for DF and HF have been calculated from the $Y_{i j}$ values in Table 4. Only the results for DF are shown in Table 5. The corresponding results for HF are essentially equal to those reported in Ref. [6]. The $B_{0}$ value of HF, for example, is calculated to be $20.55973074(153) \mathrm{cm}^{-1}$ in the present study, in contrast to $20.55973079(204) \mathrm{cm}^{-1}$ in the previous paper. In fact, the band constants for HF can be calculated easily, if necessary, from the $Y_{i j}$ values listed in Table 4 . The notations for the vibrational term values and the rotational constants in Table 5 are given by the equation for the energy levels as

$$
\begin{aligned}
F_{v}(J) & =G_{v}+B_{v} J(J+1)-D_{v}[J(J+1)]^{2}+H_{v}[J(J+1)]^{3}+L_{v}[J(J+1)]^{4}+M_{v}[J(J+1)]^{5} \\
& +N_{v}[J(J+1)]^{6}+O_{v}[J(J+1)]^{7}+P_{v}[J(J+1)]^{8}+Q_{v}[J(J+1)]^{9}+R_{v}[J(J+1)]^{10}+S_{v}[J(J+1)]^{11} .
\end{aligned}
$$

A term $Y_{00}=\left(B_{\mathrm{e}} / 8\right)\left(3 a_{2}-7 a_{1}^{2} / 4\right)$, which is not listed in Table 4, is included in the calculation of $G_{v}$. The molecular constants reported by Coxon and Hajigeorgiou [21] and the rotational constants for each vibrational state derived from the spectral analysis of DF by Ram et al. [3] are listed in this table. The Lamb-dip $J=1-0$ transition and the $J=2-1$ to 5-4 TuFIR transitions reported by Cazzoli and Puzzarini [27] and Cazzoli et al. [28], respectively, improved the ground state rotational constants of DF. Their rotational constants [28] are also included.

The agreement of the $B_{0}$ and $D_{0}$ values of this study with those of Cazzoli et al. [28] is excellent. 
Ram et al. [3] employed in their analysis the $J=1-0$ microwave (Mw) frequency obtained by DeLucia et al. [24], which was the overlapped one of the hyperfine components. By replacing the $J=1-0$ to 5-4 transition frequencies of Cazzoli and Puzzarini [27] and Cazzoli et al. [28] in the data set of the present study with those listed by Ram et al. [3], we have obtained the $B_{0}$ values as $10.86034405(86)$ $\mathrm{cm}^{-1}$ and $10.86034545(173) \mathrm{cm}^{-1}$, which are equal to those obtained by Ram et al. [3] and in this study, when uncertainties of $30 \mathrm{kHz}$ and $300 \mathrm{kHz}$ were assigned to the $J=1-0 \mathrm{Mw}$ transition, respectively.

This confirms the account of Cazzoli and Puzzarini [27] that a deviation of $1.45 \times 10^{-6} \mathrm{~cm}^{-1}$ found for the $B_{0}$ value of Ram et al. ${ }^{3}$ can be ascribed to the $J=1-0 \mathrm{Mw}$ transition, which is unresolved and affected by an uncertainty as large as $300 \mathrm{kHz}$ [27]. It is noteworthy that, when the uncertainty of 300 $\mathrm{kHz}$ is considered in the present analysis for the $J=1-0 \mathrm{Mw}$ transition, no such deviation is found for the $B_{0}=10.86034545 \mathrm{~cm}^{-1}$ value, although as much uncertainty as $1.73 \times 10^{-6} \mathrm{~cm}^{-1}$ is included. This indicates good internal consistency in the present method of analysis.

Our values of $G_{v}-G_{0}$ and from $B_{v}$ to $N_{v}$ agree well with those of Coxon and Hajigeorgiou [21], although they did not give error limits for these band constants. The spectral data set of DF of Coxon and Hajigeorgiou [21] has not included $J=1-0$ to 5-4 frequencies reported by Cazzoli and Puzzarini [27] and Cazzoli et al. [28]. Our error limits are larger than those of Ram et al. [3] and Cazzoli et al. [28] because our limits reflect the uncertainty in the potential function at a high-energy range. The error limits given by Ram et al. [3] and Cazzoli et al. [28] contain no such effects.

The terms up to $S_{v}[J(J+1)]^{11}$ need to be included in this analysis, in which the potential expansion up to $a_{9}$ is necessary to reproduce the spectral transitions. Although the vibrational terms in this study agree with those in Ref. [21], the matching of the rotational constants of orders higher than $O_{v}$ with those in Ref. [21] is not satisfactory. One reason for this discrepancy is that our constants include truncation errors; the present study does not intend to determine the potential function that extends over highly excited vibrational states that can be observed in the electronic spectra.

The values of the band constants with error limits can be easily obtained from $G_{v}$ up to $S_{v}$ in this study from a set of the fitted molecular parameters through the values of $Y_{i j}$. By the merit of the analytical approach, it is easy to reproduce the numerical values of the present potential function and 
the eigenvalues, including the effect of the breakdown of the Born-Oppenheimer approximation. Only the 20 molecular parameters determined experimentally have generated the values of the $82 Y_{i j}$ coefficients in Table 4 and the 144 rotational constants with high accuracy, among which 72 constants for DF are listed in Table 5.

\section{Acknowledgment}

We thank Professor Kozo Kuchitsu for reading the original and the revised manuscripts and providing us with helpful comments.

\section{Appendix A. Supplementary material}

Supplementary material associated with this article can be found, in the online version, at doi: 


\section{References}

[1] D. Jennings, K. M. Evenson, L. R. Zink, C. Demuynck, J. L. Destombes, B. Lemoine, J. W. C. Johns, J. Mol. Spectrosc. 122 (1987) 477.

[2] H. G. Hedderich, K. Walker, P. F. Bernath, J. Mol. Spectrosc. 149 (1991) 314.

[3] R. S. Ram, Z. Morbi, B. Guo, K. -Q. Zhang, P. F. Bernath, J. V. Auwera, J. W. C. Johns, S. P. Davis, Astrophys. J. Suppl. Ser. 103 (1996) 247.

[4] H. Odashima, L. R. Zink and K. M. Evenson, J. Mol. Spectrosc. 194 (1999) 283.

[5] D. A. Jennings, J. S. Wells, J. Mol. Spectrosc. 130 (1988) 26.

[6] H. Uehara, K. Horiai, T. Noguchi, J. Phys. Chem. A, 113 (2009) 10435.

[7] R. B. Le Blanc, J. B. White, P. F. Bernath, J. Mol. Spectrosc. 164 (1994) 574.

[8] D. Goddon, A. Groh, H. J. Hanses, M. Schneider, W. Urban, J. Mol. Spectrosc. 147 (1991) 392.

[9] A. H. M. Ross, R. S. Eng, H. Kildal, Opt. Commun. 12 (1974) 433.

[10] J. K. G. Watson, J. Mol. Spectrosc. 80 (1980) 411.

[11] E. Tiemann, H. Arnst, W. U. Stieda, T. Törring, J. Hoeft, Chem. Phys. 67 (1982) 133.

[12] C. T. Dewberry, K. C. Etchison, G. S. Grubbs II, R. A. Powoski, M. M. Serafin, S. A. Peebles, S. A. Cooke, J. Mol. Spectrosc. 248 (2008) 20.

[13] H. Uehara, J. F. Ogilvie, J. Mol. Spectrosc. 207 (2001) 143.

[14] P. R. Bunker, R. E. Moss, Mol. Phys. 33 (1977) 417.

[15] M. Gruebele. E. Keim, A. Stein, R. J. Saykally, J. Mol. Spectrosc. 131 (1988) 343.

[16] R. M. Herman, J. F. Ogilvie, Adv. Chem. Phys. 103 (1998) 187.

[17] J. K. G. Watson, J. Mol. Spectrosc. 217 (2003) 157.

[18] J. A. Coxon, P. G. Hajigeorgiou, Chem. Phys. 167 (1992) 327.

[19] J. A. Coxon, J. F. Ogilvie, Can. J. Spectrosc. 34 (1989) 137.

[20] J. A. Coxon, P. G. Hajigeorgiou, J. Mol. Spectrosc. 142 (1990) 254.

[21] J. A. Coxon, P. G. Hajigeorgiou, J. Phys. Chem. A, 110 (2006) 6261.

[22] K. P. Huber, G. Herzberg, Molecular Spectra and Molecular Structure IV. Constants of Diatomic Molecules, Van Nostrand, New York, 1979. 
[23] P. Helminger, F. C. De Lucia, W. Gordy, Phys. Rev. Lett. 25 (1970) 1397.

[24] F. C. De Lucia, P. Helminger, W. Gordy, Phys. Rev. A, 3 (1971) 1849.

[25] R. N. Spanbauer, K. N. Rao, L. H. Jones, J. Mol. Spectrosc. 16 (1965) 100.

[26] U. K. Sengupta, P. K. Das, K. N. Rao, J. Mol. Spectrosc. 74 (1979) 322.

[27] G. Cazzoli, C. Puzzarini, J. Mol. Spectrosc. 231 (2005) 124.

[28] G. Cazzoli, C. Puzzarini, F. Tamassia, S. Borri, S. Bartalini, J. Mol. Spectrosc. 235 (2006) 265.

[29] R. M. Herman, A. Asgharian, J. Mol. Spectrosc. 19 (1966) 305.

[30] P. R. Bunker, J. Mol. Spectrosc. 68 (1977) 367.

[31] J. L. Dunham, Phys. Rev. 41 (1932) 721.

[32] H. Uehara, Bull. Chem. Soc. Jpn. 77 (2004) 2189.

[33] E. R. Cohen, T. Cvitas, J. G. Frey, B. Holmström, K. Kuchitsu, R. Marquardt, I. Mills, F. Pavese, M. Quack, J. Stohner, H. L. strauss, M. Takami, A. J. Thor, Quantities, Units and Symbols in Physical Chemistry, third ed. RSC Publishing, Cambridge, 2007.

[34] B. M. Giuliano, L. Bizzocchi, J.-U. Grabow, J. Mol. Spectrosc. 251 (2008) 261.

[35] B. M. Giuliano, L. Bizzocchi, S. Cooke, D. Banser, M. Hess, J. Fritzsche, J.-U. Grabow, Phys. Chem. Chem. Phys. 10 (2008) 2078. 
Table 1 Definition of the non-Born-Oppenheimer parameters.

All the parameters are isotopically invariant.

Parameters for the

nuclei $\mathrm{H}$ and $\mathrm{F}$
Corrections for the breakdown of the

Born-Oppenheimer approximation
$\Delta_{\omega}^{\mathrm{H}}$ and $\Delta_{\omega}^{\mathrm{F}}$

$\Delta_{B}{ }^{\mathrm{H}}$ and $\Delta_{B}{ }^{\mathrm{F}}$

$\Delta_{a 1 q}{ }^{\mathrm{H}}, \Delta_{a 2 q}{ }^{\mathrm{H}}, .$. and $\Delta_{a 1 q}$,

$\Delta_{a 2 q}{ }^{\mathrm{F}}, .$.

$r_{1 q}^{\mathrm{H}}, r_{2 q}^{\mathrm{H}}, .$. and $r_{1 q}^{\mathrm{F}}, r_{2 q}^{\mathrm{F}}, .$. for the reduced harmonic vibrational wavenumber

$U_{\omega}$, where $U_{\omega}=\mu^{1 / 2} \omega_{\mathrm{e}}$.

for the reduced equilibrium rotational constant $U_{B}$, where $U_{B}=\mu B_{\text {e }}$.

for the Dunham potential constants, $a_{1}, a_{2}, \ldots$.

for the radial part of the rotational energy;

$$
\frac{B_{e}\left(1+\delta \Delta_{B}\right)}{\left(1+\xi^{\prime}\right)^{2}}\left(1+\sum_{i=1} \delta r_{i q}\left(\xi^{\prime}\right)^{i}\right) J(J+1), \text { where, }
$$

e.g., $\delta \Delta_{B}=m_{\mathrm{e}} \Delta_{B}{ }^{\mathrm{H}} / M_{\mathrm{H}}+m_{\mathrm{e}} \Delta_{B}{ }^{\mathrm{F}} / M_{\mathrm{F}}$, and $\xi^{\prime}$ is given in equation 5 in the text. 
Table 2 Non-Born-Oppenheimer parameters expressed in terms of the expansion coefficients $q_{i}^{H, F}, r_{i}^{H, F}$, and $s_{i}^{H, F}$.

Parameters and expressions with the expansion coefficients

$$
\begin{aligned}
& \Delta_{\omega}^{\mathrm{H}, \mathrm{F}}=-\left(B_{\mathrm{e}} / \omega_{\mathrm{e}}{ }^{2}\right)\left(3 a_{1} s_{1}{ }^{\mathrm{H}, \mathrm{F}}-2 s_{2}{ }^{\mathrm{H}, \mathrm{F}}\right)+q_{0}{ }^{\mathrm{H}, \mathrm{F}} / 2 \\
& \Delta_{B}{ }^{\mathrm{H}, \mathrm{F}}= r_{0}{ }^{\mathrm{H}, \mathrm{F}}+\left(4 B_{\mathrm{e}} / \omega_{\mathrm{e}}{ }^{2}\right) s_{1}{ }^{\mathrm{H}, \mathrm{F}} \\
& \Delta_{a 1 q}{ }^{\mathrm{H}, \mathrm{F}}=-\left(2 B_{\mathrm{e}} / \omega_{\mathrm{e}}{ }^{2}\right)\left\{\left(1-3 a_{1}+4 a_{2} / a_{1}\right) s_{1}{ }^{\mathrm{H}, \mathrm{F}}+2 s_{2}{ }^{\mathrm{H}, \mathrm{F}}-2 s_{3}{ }^{\mathrm{H}, \mathrm{F}} / a_{1}\right\} \\
&-\left(r_{0}{ }^{\mathrm{H}, \mathrm{F}}-q_{0}{ }^{\mathrm{H}, \mathrm{F}}\right) / 2+q_{1}{ }^{\mathrm{H}, \mathrm{F}} / 2 a_{1} \\
& \Delta_{a 2 q}{ }^{\mathrm{H}, \mathrm{F}}=-\left(2 B_{\mathrm{e}} / \omega_{\mathrm{e}}{ }^{2}\right)\left\{\left(2-3 a_{1}+5 a_{3} / a_{2}\right) s_{1}{ }^{\mathrm{H}, \mathrm{F}}+2 s_{2}{ }^{\mathrm{H}, \mathrm{F}}-2 s_{4}{ }^{\mathrm{H}, \mathrm{F}} / a_{2}\right\} \\
&-\left(r_{0}{ }^{\mathrm{H}, \mathrm{F}}-q_{0}{ }^{\mathrm{H}, \mathrm{F}}\right)+3 a_{1} q_{1}{ }^{\mathrm{H}, \mathrm{F}} / 4 a_{2}+q_{2}{ }^{\mathrm{H}, \mathrm{F}} / 3 a_{2} \\
& \Delta_{a 3 q}{ }^{\mathrm{H}, \mathrm{F}}=-\left(2 B_{\mathrm{e}} / \omega_{\mathrm{e}}{ }^{2}\right)\left\{\left(3-3 a_{1}+6 a_{4} / a_{3}\right) s_{1}{ }^{\mathrm{H}, \mathrm{F}}+2 s_{2}{ }^{\mathrm{H}, \mathrm{F}}-2 s_{5}{ }^{\mathrm{H}, \mathrm{F}} / a_{3}\right\} \\
& r_{1 q}{ }^{\mathrm{H}}\left(=r_{1 q}{ }^{\mathrm{F}}\right)= r_{1}{ }^{\mathrm{H}}+\left(r_{0}{ }^{\mathrm{H}}-q_{0}{ }^{\mathrm{H}}\right) \\
& r_{2 q}{ }^{\mathrm{H}}\left(=r_{2 q}{ }^{\mathrm{F}}\right)= r_{2}{ }^{\mathrm{H}}-\left(r_{0}{ }^{\mathrm{H}}-q_{0}{ }^{\mathrm{H}}\right)-q_{1}{ }^{\mathrm{H}} / 2 \\
& r_{3 q}{ }^{\mathrm{H}}\left(=r_{3 q}{ }^{\mathrm{F}}\right)= r_{3}{ }^{\mathrm{H}}+\left(r_{0}{ }^{\mathrm{H}}-q_{0}{ }^{\mathrm{H}}\right)+q_{1}{ }^{\mathrm{H}} / 2-q_{2}{ }^{\mathrm{H}} / 3 \\
& r_{4 q}{ }^{\mathrm{H}}\left(=r_{4 q}{ }^{\mathrm{F}}\right)= r_{4}{ }^{\mathrm{H}}-\left(r_{0}{ }^{\mathrm{H}}-q_{0}{ }^{\mathrm{H}}\right)-q_{1}{ }^{\mathrm{H}} / 2+q_{2}{ }^{\mathrm{H}} / 3-q_{3}{ }^{\mathrm{H}} / 4 \\
&
\end{aligned}
$$


Table 3 Irreducible molecular constants of HF.

\begin{tabular}{|c|c|}
\hline Parameters & Fitted \\
\hline$U_{\omega}\left(1+m_{\mathrm{e}} \Delta_{\omega}^{\mathrm{F}} / M_{\mathrm{F}}\right) / \mathrm{cm}^{-1} \mathrm{u}^{1 / 2}$ & $4048.449190(711)^{a}$ \\
\hline$U_{B}\left(1+m_{\mathrm{e}} \Delta_{B}^{\mathrm{F}} / M_{\mathrm{F}}\right) / \mathrm{cm}^{-1} \mathrm{u}$ & $20.04811294(103)$ \\
\hline$a_{1}\left(1+m_{\mathrm{e}} \Delta_{a 1 q}^{\mathrm{F}} / M_{\mathrm{F}}\right)$ & $-2.24633825(541)$ \\
\hline$a_{2}\left(1+m_{\mathrm{e}} \Delta_{a 2 q}{ }^{\mathrm{F}} / M_{\mathrm{F}}\right)$ & $3.4449250(340)$ \\
\hline$a_{3}\left(1+m_{\mathrm{e}} \Delta_{a 3 q}{ }^{\mathrm{F}} / M_{\mathrm{F}}\right)$ & $-4.453696(151)$ \\
\hline$a_{4}$ & $5.160449(674)$ \\
\hline$a_{5}$ & $-5.53110(353)$ \\
\hline$a_{6}$ & $5.4599(126)$ \\
\hline$a_{7}$ & $-4.7776(315)$ \\
\hline$a_{8}$ & $3.788(115)$ \\
\hline$a_{9}$ & $-4.951(531)$ \\
\hline$\Delta_{\omega}^{\mathrm{H}}$ & $0.127696(176)$ \\
\hline$\Delta_{B}{ }^{\mathrm{H}}$ & $0.579039(124)$ \\
\hline$\Delta_{a 1 q}{ }^{\mathrm{H}}$ & $-0.30375(817)$ \\
\hline$\Delta_{a 2 q}{ }^{\mathrm{H}}$ & $-0.4125(297)$ \\
\hline$\Delta_{a 3 q^{\mathrm{H}}}$ & $-0.3979(659)$ \\
\hline$r_{1 q}^{\mathrm{H}}\left(=r_{l q}{ }^{\mathrm{F}}\right)$ & $-0.10600(331)$ \\
\hline$r_{2 q}{ }^{\mathrm{H}}\left(=r_{2 q}{ }^{\mathrm{F}}\right)$ & $-0.9149(526)$ \\
\hline$r_{3 q}{ }^{\mathrm{H}}\left(=r_{3 q}{ }^{\mathrm{F}}\right)$ & $0.521(105)$ \\
\hline$r_{4 q}^{\mathrm{H}}\left(=r_{4 q}{ }^{\mathrm{F}}\right)$ & $0.654(331)$ \\
\hline Reduced standard deviation & 1.19 \\
\hline
\end{tabular}

${ }^{a}$ The uncertainty (one standard error) in the last digit is given in parentheses. 
Table 4 Values of the Dunham coefficients $Y_{i j}$ (in units of $\mathrm{cm}^{-1}$ ) for DF and HF back-calculated from 20 molecular constants given in Table 1.

\begin{tabular}{|c|c|c|c|c|c|}
\hline Coeff. & DF & $\mathrm{HF}$ & Coeff. & DF & $\mathrm{HF}$ \\
\hline$Y_{10}$ & $3000.081232(512)^{a}$ & $4138.381218(747)$ & $10^{11} Y_{04}$ & $-0.11910661(613)$ & $-1.562697(128)$ \\
\hline$Y_{20}$ & $-47.270368(376)$ & $-89.939974(725)$ & $10^{14} Y_{14}$ & $0.4875(103)$ & $8.824(186)$ \\
\hline$Y_{30}$ & $0.351748(110)$ & $0.923482(289)$ & $10^{14} Y_{24}$ & $-0.14844(299)$ & $-3.7065(746)$ \\
\hline $10^{2} Y_{40}$ & $-0.42425(141)$ & $-1.53660(511)$ & $10^{16} Y_{34}$ & $0.7410(726)$ & $25.53(250)$ \\
\hline $10^{4} Y_{50}$ & $-0.88957(663)$ & $-4.4450(331)$ & $10^{16} Y_{05}$ & $0.643570(137)$ & $16.07446(490)$ \\
\hline$Y_{01}$ & $11.010690394(391)$ & $20.953688563(940)$ & $10^{18} Y_{15}$ & $-0.4924(299)$ & $-16.96(103)$ \\
\hline$Y_{11}$ & $-0.302178023(995)$ & $-0.79329125(228)$ & $10^{18} Y_{25}$ & $-0.1548(124)$ & $-7.357(591)$ \\
\hline $10^{2} Y_{21}$ & $0.2994780(995)$ & $1.084705(160)$ & $10^{19} Y_{35}$ & $-0.3132(210)$ & $-20.53(138)$ \\
\hline $10^{4} Y_{31}$ & $-0.374622(834)$ & $-1.87189(417)$ & $10^{20} Y_{06}$ & $-0.424536(277)$ & $-20.1752(132)$ \\
\hline $10^{5} Y_{41}$ & $-0.129152(619)$ & $-0.89030(427)$ & $10^{21} Y_{16}$ & $-0.202498(422)$ & $-13.276(277)$ \\
\hline $10^{7} Y_{51}$ & $-0.13580(354)$ & $-1.2914(336)$ & $10^{22} Y_{26}$ & $0.3230(346)$ & $29.22(313)$ \\
\hline $10^{3} Y_{02}$ & $-0.593276078(585)$ & $-2.14890408(412)$ & $10^{24} Y_{07}$ & $0.272489(663)$ & $24.6458(599)$ \\
\hline $10^{4} Y_{12}$ & $0.11689240(679)$ & $0.5840961(420)$ & $10^{26} Y_{17}$ & $0.9932(966)$ & $123.9(121)$ \\
\hline $10^{6} Y_{22}$ & $-0.151315(379)$ & $-1.04307(261)$ & $10^{25} Y_{27}$ & $-0.10324(809)$ & $-17.77(139)$ \\
\hline $10^{8} Y_{32}$ & $-0.50091(718)$ & $-4.7636(683)$ & $10^{28} Y_{08}$ & $-0.220922(887)$ & $-38.030(153)$ \\
\hline $10^{9} Y_{42}$ & $-0.17918(494)$ & $-2.3508(648)$ & $10^{31} Y_{18}$ & $-0.54(269)$ & $-128.3(6384)$ \\
\hline $10^{7} Y_{03}$ & $0.24088748(360)$ & $1.6605177(482)$ & $10^{32} Y_{09}$ & $0.16076(116)$ & $52.667(379)$ \\
\hline $10^{9} Y_{13}$ & $-0.466986(301)$ & $-4.43931(366)$ & $10^{33} Y_{19}$ & $0.9315(583)$ & $421.0(264)$ \\
\hline $10^{11} Y_{23}$ & $-0.6788(137)$ & $-8.906(180)$ & $10^{36} Y_{010}$ & $-0.12134(267)$ & $-75.66(166)$ \\
\hline $10^{11} Y_{33}$ & $-0.10865(273)$ & $-1.9665(494)$ & $10^{41} Y_{011}$ & $0.5901(550)$ & $700.3(653)$ \\
\hline $10^{14} Y_{43}$ & $-0.181(156)$ & $-4.52(389)$ & $Y_{00}$ & $2.070008(152)$ & $3.938725(289)$ \\
\hline
\end{tabular}

\footnotetext{
${ }^{a}$ The uncertainty (one standard error) in the last digit is given in parentheses.
} 
Table 5 Band constants (in units of $\mathrm{cm}^{-1}$ ) for DF calculated from $41 Y_{i j}$ given in Table 2.

\begin{tabular}{|c|c|c|c|c|c|c|c|c|c|}
\hline$v$ & $G_{v}$ & \multicolumn{2}{|l|}{$G_{v}-G_{0}$} & \multicolumn{2}{|l|}{$B_{v}$} & \multicolumn{2}{|c|}{$10^{4} D_{v}$} & $10^{8} H_{v}$ & $10^{12} L_{v}$ \\
\hline 0 & $\begin{array}{l}1490.336733(273 \\
1490.33540\end{array}$ & \multicolumn{2}{|l|}{$\begin{array}{l}0.0 \\
0.0 \\
0.0\end{array}$} & \multicolumn{2}{|c|}{$\begin{array}{l}10.860345314(644) \\
10.860344769 \\
10.86034387(20) \\
10.8603453163(70)\end{array}$} & \multicolumn{2}{|c|}{$\begin{array}{l}5.87469923(683) \\
5.87468735 \\
5.874588(31) \\
5.874698(30)\end{array}$} & $\begin{array}{l}2.3853421(392) \\
2.3852372 \\
2.38133(54) \\
2.38258(53)\end{array}$ & $\begin{array}{l}-1.1889902(803) \\
-1.188680 \\
-1.1428(34) \\
-1.1484(33)\end{array}$ \\
\hline 1 & $\begin{array}{l}4396.99852(120) \\
4396.99697\end{array}$ & \multicolumn{2}{|c|}{$\begin{array}{l}2906.66179(123) \\
2906.66157 \\
2906.661542(15)\end{array}$} & \multicolumn{2}{|c|}{$\begin{array}{l}10.56402854(190) \\
10.564028043 \\
10.56402755(48)\end{array}$} & \multicolumn{2}{|c|}{$\begin{array}{l}5.7610049(147) \\
5.76098212 \\
5.760898(41)\end{array}$} & $\begin{array}{l}2.3369318(662) \\
2.3367700 \\
2.33271(78)\end{array}$ & $\begin{array}{l}-1.186843(181) \\
-1.186116 \\
-1.1386(55)\end{array}$ \\
\hline 2 & $\begin{array}{l}7212.15494(323) \\
7212.15320\end{array}$ & \multicolumn{2}{|c|}{$\begin{array}{l}5721.81821(324) \\
5721.81780 \\
5721.818201(94)\end{array}$} & \multicolumn{2}{|c|}{$\begin{array}{l}10.27332559(413) \\
10.273325569 \\
10.2733195(15)\end{array}$} & \multicolumn{2}{|c|}{$\begin{array}{l}5.6508396(318) \\
5.65079218 \\
5.650154(63)\end{array}$} & $\begin{array}{l}2.286181(127) \\
2.2858331 \\
2.26777(79)\end{array}$ & $\begin{array}{l}-1.186997(343) \\
-1.184902 \\
-1.0094(29)\end{array}$ \\
\hline 3 & $\begin{array}{l}9937.69014(717) \\
9937.68872\end{array}$ & \multicolumn{2}{|c|}{$\begin{array}{l}8447.35341(718) \\
8447.35332 \\
8447.35379(15)\end{array}$} & \multicolumn{2}{|c|}{$\begin{array}{l}9.98794623(777) \\
9.987946445 \\
9.9879411(31)\end{array}$} & \multicolumn{2}{|c|}{$\begin{array}{l}5.5445899(613) \\
5.54449231 \\
5.54395(17)\end{array}$} & $\begin{array}{l}2.232428(234) \\
2.231415 \\
2.2147(30)\end{array}$ & $\begin{array}{l}-1.189009(603) \\
-1.18444 \\
-1.018\end{array}$ \\
\hline 4 & $\begin{array}{l}12575.3598(141) \\
12575.35897\end{array}$ & \multicolumn{2}{|c|}{$\begin{array}{l}11085.0231(141) \\
11085.02357 \\
11085.02390(23)\end{array}$} & \multicolumn{2}{|c|}{$\begin{array}{l}9.7075652(134) \\
9.707559908 \\
9.7075572(75)\end{array}$} & \multicolumn{2}{|c|}{$\begin{array}{l}5.442685(107) \\
5.4424906 \\
5.44187(68)\end{array}$} & $\begin{array}{l}2.175010(404) \\
2.173211 \\
2.147(22)\end{array}$ & $\begin{array}{l}-1.19243(101) \\
-1.18730 \\
-0.88(22)\end{array}$ \\
\hline 5 & $\begin{array}{l}15126.7804(255) \\
15126.78000\end{array}$ & \multicolumn{2}{|c|}{$\begin{array}{l}13636.4437(255) \\
13636.44460 \\
13636.44457(34)\end{array}$} & \multicolumn{2}{|c|}{$\begin{array}{l}9.4318204(216) \\
9.43180391 \\
9.4318026(97)\end{array}$} & \multicolumn{2}{|c|}{$\begin{array}{l}5.345599(176) \\
5.3452748 \\
5.34397(69)\end{array}$} & $\begin{array}{l}2.113255(654) \\
2.110928 \\
2.038(13)\end{array}$ & $\begin{array}{l}-1.19683(161) \\
-1.19651\end{array}$ \\
\hline$v$ & $10^{17} M_{v}$ & $10^{21} N_{v}$ & & ${ }^{25} O_{v}$ & $10^{29} P_{v}$ & & $10^{33} Q_{v}$ & $10^{37} R_{v}$ & $10^{42} S_{v}$ \\
\hline 0 & $\begin{array}{l}6.40682(205) \\
6.397970 \\
4.187(69) \\
4.283(70)\end{array}$ & $\begin{array}{l}-4.33854(359) \\
-4.30750\end{array}$ & & $\begin{array}{l}4874(845) \\
347\end{array}$ & $\begin{array}{l}-2.2119(16 \\
-1.805\end{array}$ & 61) & $\begin{array}{l}2.0733(314) \\
0.645\end{array}$ & $\begin{array}{l}-1.2134(267) \\
-0.717\end{array}$ & $\begin{array}{l}5.901(550) \\
32.4\end{array}$ \\
\hline 1 & $\begin{array}{l}6.31644(551) \\
6.28143 \\
4.03(13)\end{array}$ & $\begin{array}{l}-4.4764(104) \\
-4.3003\end{array}$ & & $\begin{array}{l}416(242) \\
17\end{array}$ & $\begin{array}{l}-2.2173(41 \\
-1.392\end{array}$ & 13) & $\begin{array}{l}3.0048(823) \\
3.143\end{array}$ & $\begin{array}{l}-1.2134 \\
-8.921\end{array}$ & $\begin{array}{l}5.901 \\
93.4\end{array}$ \\
\hline 2 & $\begin{array}{l}6.1669(114) \\
6.04293\end{array}$ & $\begin{array}{l}-4.5497(242) \\
-4.1673\end{array}$ & & $\begin{array}{l}280(564) \\
40\end{array}$ & $\begin{array}{l}-2.2227(67 \\
-4.326\end{array}$ & 78) & $\begin{array}{l}3.936(146) \\
7.805\end{array}$ & $\begin{array}{l}-1.2134 \\
-6.256\end{array}$ & $\begin{array}{l}5.901 \\
-222.8\end{array}$ \\
\hline 3 & $\begin{array}{l}5.9394(206) \\
5.8079\end{array}$ & $\begin{array}{l}-4.5584(450) \\
-4.4454\end{array}$ & & $\begin{array}{l}08(105) \\
94\end{array}$ & $\begin{array}{l}-2.2281(94 \\
-7.076\end{array}$ & 45) & $\begin{array}{l}4.868(204) \\
5.194\end{array}$ & $\begin{array}{l}-1.2134 \\
20.842\end{array}$ & $\begin{array}{r}5.901 \\
1055.5\end{array}$ \\
\hline 4 & $\begin{array}{l}5.6152(344) \\
5.6242\end{array}$ & $\begin{array}{l}-4.5025(727) \\
-5.1493\end{array}$ & & $\begin{array}{l}81(170) \\
13\end{array}$ & $\begin{array}{l}-2.234(121 \\
-6.150\end{array}$ & 1) & $\begin{array}{l}5.799(263) \\
12.199\end{array}$ & $\begin{array}{l}-1.2134 \\
81.416\end{array}$ & $\begin{array}{l}5.901 \\
2422.4\end{array}$ \\
\hline 5 & $\begin{array}{l}5.1754(539) \\
5.4782\end{array}$ & $\begin{array}{l}-4.381(107) \\
-6.0138\end{array}$ & & $\begin{array}{l}8(251) \\
85\end{array}$ & $\begin{array}{l}-2.239(148 \\
1.631\end{array}$ & 8) & $\begin{array}{l}6.731(321) \\
49.541\end{array}$ & $\begin{array}{l}-1.2134 \\
177.813\end{array}$ & $\begin{array}{l}5.901 \\
4195.5\end{array}$ \\
\hline
\end{tabular}

${ }^{a}$ The uncertainty (one standard error) in the last digit is given in parentheses. The second, third, and fourth row entries are the values reported in Refs. [21], [3], and [28], respectively. 


\title{
Supplementary material for
}

\section{Simultaneous analysis of rotational and vibrational-rotational spectra of DF and HF to obtain irreducible molecular constants for HF}

\author{
Koui Horiai and Hiromichi Uehara
}

Explicit expressions for the modified Dunham coefficients $Y_{10} *, Y_{20} *, Y_{01} *, Y_{11} *$, and $Y_{02} *$

$$
\begin{aligned}
& Y_{10} *=\omega_{\mathrm{e}}\left(1+\delta \Delta_{\omega}\right)+Y_{10}{ }^{(2)}, \\
& Y_{20} *=-\left\{B_{\mathrm{e}}\left(1+\delta \Delta_{B}\right) / 8\right\}\left[15\left\{a_{1}\left(1+\delta \Delta_{a 1 q}\right)\right\}^{2}-12 a_{2}\left(1+\delta \Delta_{a 2 q}\right)\right]+Y_{20}{ }^{(2)}, \\
& Y_{01} *=B_{\mathrm{e}}\left(1+\delta \Delta_{B}\right)+Y_{01}{ }^{(2)}, \\
& Y_{11} *=\left[\left\{B_{\mathrm{e}}\left(1+\delta \Delta_{B}\right)\right\}^{2} /\left\{\omega_{\mathrm{e}}\left(1+\delta \Delta_{\omega}\right)\right\}\right]\left\{6+6 a_{1}\left(1+\delta \Delta_{a 1 q}\right)-\left(4+3 a_{1}\right) \delta r_{1 q}+2 \delta r_{2 q}\right\}+Y_{11}{ }^{(2)},
\end{aligned}
$$

and

$Y_{02} *=-\left[4\left\{B_{\mathrm{e}}\left(1+\delta \Delta_{B}\right)\right\}^{3} /\left\{\omega_{\mathrm{e}}\left(1+\delta \Delta_{\omega}\right)\right\}^{2}\right]\left(1-\delta r_{1 q}\right)+Y_{02}{ }^{(2)}$. 
Table S1 Fitted rotational and vibrational-rotational transitions for DF in a single set of DF and HF data.

\begin{tabular}{|c|c|c|c|c|c|c|c|c|c|c|c|}
\hline$J^{\prime}$ & $J^{\prime \prime}$ & obs. $/ \mathrm{cm}^{-1}$ & $J^{\prime}$ & $J^{\prime \prime}$ & obs./.cm ${ }^{-1}$ & $J^{\prime}$ & $J^{\prime \prime}$ & obs. $/ \mathrm{cm}^{-1}$ & $J^{\prime}$ & $J^{\prime \prime}$ & obs. $/ \mathrm{cm}^{-1}$ \\
\hline $\mathrm{v}=0$ & & & 39 & 38 & $698.76560(-13)^{d}$ & 15 & 14 & $3154.18060(-11)^{d}$ & 2 & 3 & $2662.24460(25)^{d}$ \\
\hline 1 & 0 & $21.71834094(0)^{a, b}$ & 40 & 39 & $710.59057(10)^{d}$ & 16 & 15 & $3164.94859(-15)^{d}$ & 1 & 2 & $2683.88959(33)^{d}$ \\
\hline 2 & 1 & $43.4225887(15)^{c}$ & 42 & 41 & $733.01159(77)^{d}$ & 17 & 16 & $3174.94579(-19)^{d}$ & 0 & 1 & $2704.99136(55)^{d}$ \\
\hline 3 & 2 & $65.0986681(70)^{c}$ & 43 & 42 & $743.59754(-55)^{d}$ & 18 & 17 & $3184.16451(-35)^{d}$ & 1 & 0 & $2745.50964(76)^{d}$ \\
\hline 4 & 3 & $86.7325205(8)^{c}$ & 44 & 43 & $753.76597(93)^{d}$ & 19 & 18 & $3192.59843(11)^{d}$ & 2 & 1 & $2764.89905(52)^{d}$ \\
\hline 5 & 4 & $108.3101694(-12)^{c}$ & & & & 20 & 19 & $3200.23886(-90)^{d}$ & 3 & 2 & $2783.69155(41)^{d}$ \\
\hline 2 & 1 & $43.42268(9)^{d}$ & $\mathrm{v}=2$ & & & 21 & 20 & $3207.08299(-8)^{d}$ & 4 & 3 & $2801.87440(45)^{d}$ \\
\hline 3 & 2 & $65.09863(-3)^{d}$ & 12 & 11 & $242.68774(-9)^{d}$ & 22 & 21 & $3213.12290(28)^{d}$ & 5 & 4 & $2819.43496(44)^{d}$ \\
\hline 4 & 3 & $86.73251(-1)^{d}$ & 13 & 12 & $262.19099(4)^{d}$ & 23 & 22 & $3218.35365(37)^{d}$ & 6 & 5 & $2836.36109(37)^{d}$ \\
\hline 5 & 4 & $108.31021(4)^{d}$ & 14 & 13 & $281.52421(55)^{d}$ & 24 & 23 & $3222.76947(-92)^{d}$ & 7 & 6 & $2852.64122(46)^{d}$ \\
\hline 6 & 5 & $129.81770(1)^{d}$ & 15 & 14 & $300.67460(75)^{d}$ & 25 & 24 & $3226.36891(-87)^{d}$ & 8 & 7 & $2868.26355(37)^{d}$ \\
\hline 7 & 6 & $151.24126(2)^{d}$ & 16 & 15 & $319.63003(44)^{d}$ & 26 & 25 & $3229.14685(-92)^{d}$ & 9 & 8 & $2883.21728(39)^{d}$ \\
\hline 8 & 7 & $172.56709(1)^{d}$ & 17 & 16 & $338.37971(52)^{d}$ & 27 & 26 & $3231.10055(-60)^{d}$ & 10 & 9 & $2897.49155(39)^{d}$ \\
\hline 9 & 8 & $193.78167(8)^{d}$ & 18 & 17 & $356.91081(-38)^{d}$ & 28 & 27 & $3232.22458(-261)^{d}$ & 11 & 10 & $2911.07610(46)^{d}$ \\
\hline 13 & 12 & $277.26032(138)^{d}$ & 26 & 25 & $496.04432(169)^{d}$ & 30 & 29 & $3231.98674(-196)^{d}$ & 12 & 11 & $2923.96068(30)^{d}$ \\
\hline 14 & 13 & $297.71830(59)^{d}$ & 27 & 26 & $512.14415(65)^{d}$ & 32 & 31 & $3228.42054(77)^{d}$ & 13 & 12 & $2936.13615(35)^{d}$ \\
\hline 15 & 14 & $317.98717(42)^{d}$ & 28 & 24 & $527.92766(74)^{d}$ & & & & 14 & 13 & $2947.59304(26)^{d}$ \\
\hline 16 & 15 & $338.05451(82)^{d}$ & 29 & 28 & $543.38427(-26)^{d}$ & $\mathrm{v}=2$ & & & 15 & 14 & $2958.32288(32)^{d}$ \\
\hline 17 & 16 & $357.90753(115)^{d}$ & 30 & 29 & $558.50832(3)^{d}$ & 20 & 21 & $2272.06406(176)^{d}$ & 16 & 15 & $2968.31793(108)^{d}$ \\
\hline 19 & 18 & $396.92146(-22)^{d}$ & 31 & 30 & $573.29046(0)^{d}$ & 18 & 19 & $2331.03972(188)^{d}$ & 18 & 17 & $2986.06815(30)^{d}$ \\
\hline 20 & 19 & $416.06039(-87)^{d}$ & 32 & 31 & $587.72335(-27)^{d}$ & 15 & 16 & $2417.26117(71)^{d}$ & 19 & 18 & $2993.81081(70)^{d}$ \\
\hline 21 & 20 & $434.93993(-62)^{d}$ & 33 & 32 & $601.80018(-49)^{d}$ & 14 & 15 & $2445.34320(181)^{d}$ & 20 & 19 & $3000.78863(66)^{d}$ \\
\hline 22 & 21 & $453.54830(-45)^{d}$ & 34 & 33 & $615.51490(7)^{d}$ & 13 & 14 & $2473.06664(38)^{d}$ & 21 & 20 & $3006.99533(2)^{d}$ \\
\hline 23 & 22 & $471.87491(-40)^{d}$ & 35 & 34 & $628.85956(-5)^{d}$ & 12 & 13 & $2500.41979(41)^{d}$ & 23 & 22 & $3017.07655(42)^{d}$ \\
\hline 24 & 23 & $489.90965(-38)^{d}$ & 36 & 35 & $641.82869(-16)^{d}$ & 11 & 12 & $2527.38536(26)^{d}$ & 24 & 23 & $3020.93938(-20)^{d}$ \\
\hline 25 & 24 & $507.64260(-39)^{d}$ & 37 & 36 & $654.41807(138)^{d}$ & 10 & 11 & $2553.94798(19)^{d}$ & & & \\
\hline 26 & 25 & $525.06428(-29)^{d}$ & 38 & 37 & $666.61712(-47)^{d}$ & 9 & 10 & $2580.09193(6)^{d}$ & \multicolumn{3}{|c|}{$\mathrm{v}=4-3$} \\
\hline 27 & 26 & $542.16514(-38)^{d}$ & 39 & 38 & $678.42581(-49)^{d}$ & 8 & 9 & $2605.80199(14)^{d}$ & 10 & 11 & $2390.14589(-6)^{d}$ \\
\hline 28 & 27 & $558.93647(-39)^{d}$ & & & & 7 & 8 & $2631.06221(-10)^{d}$ & 9 & 10 & $2414.96323(18)^{d}$ \\
\hline 29 & 28 & $575.36984(-14)^{d}$ & $v=3$ & & & 6 & 7 & $2655.85791(-2)^{d}$ & 8 & 9 & $2439.35953(-117)^{d}$ \\
\hline 30 & 29 & $591.45645(-15)^{d}$ & 28 & 27 & $512.82225(-39)^{d}$ & 5 & 6 & $2680.17336(-18)^{d}$ & 7 & 8 & $2463.32447(30)^{d}$ \\
\hline 31 & 30 & $607.18887(12)^{d}$ & 29 & 28 & $527.80356(130)^{d}$ & 4 & 5 & $2703.99395(-13)^{d}$ & 6 & 7 & $2486.83912(33)^{d}$ \\
\hline 32 & 31 & $622.55881(-1)^{d}$ & 30 & 29 & $542.45396(15)^{d}$ & 3 & 4 & $2727.30446(-21)^{d}$ & 5 & 6 & $2509.89038(36)^{d}$ \\
\hline 33 & 32 & $637.55972(18)^{d}$ & 31 & 30 & $556.76868(-94)^{d}$ & 2 & 3 & $2750.09018(-43)^{d}$ & 4 & 5 & $2532.46382(38)^{d}$ \\
\hline 34 & 33 & $652.18408(10)^{d}$ & 32 & 31 & $570.74235(1)^{d}$ & 1 & 2 & $2772.33720(-17)^{d}$ & 3 & 4 & $2554.54475(-3)^{d}$ \\
\hline 35 & 34 & $666.42552(-2)^{d}$ & 33 & 32 & $584.36585(94)^{d}$ & 0 & 1 & $2794.03091(25)^{d}$ & 2 & 3 & $2576.12051(61)^{d}$ \\
\hline 36 & 35 & $680.27762(-35)^{d}$ & & & & 1 & 0 & $2835.69993(-88)^{d}$ & 1 & 2 & $2597.17542(54)^{d}$ \\
\hline 37 & 36 & $693.73522(-13)^{d}$ & & & & 2 & 1 & $2855.65012(-16)^{d}$ & 1 & 0 & $2657.08308(48)^{d}$ \\
\hline 38 & 37 & $706.79187(-23)^{d}$ & \multicolumn{2}{|c|}{$\mathrm{v}=1-0$} & & 3 & 2 & $2874.99153(-2)^{d}$ & 2 & 1 & $2675.92015(-163)$ \\
\hline 39 & 38 & $719.44246(-52)^{d}$ & 24 & 25 & $2225.21791(54)^{d}$ & 4 & 3 & $2893.71165(0)^{d}$ & 3 & 2 & $2694.17510(73)^{d}$ \\
\hline 40 & 39 & $731.68274(-32)^{d}$ & 23 & 24 & $2256.56754(-40)^{d}$ & 5 & 4 & $2911.79761(-30)^{d}$ & 4 & 3 & $2711.82851(64)^{d}$ \\
\hline 41 & 40 & $743.50766(-9)^{d}$ & 22 & 23 & $2287.69949(93)^{d}$ & 6 & 5 & $2929.23772(-26)^{d}$ & 5 & 4 & $2728.87050(47)^{d}$ \\
\hline 42 & 41 & $754.91261(-17)^{d}$ & 21 & 22 & $2318.59414(37)^{d}$ & 7 & 6 & $2946.01971(-15)^{d}$ & 6 & 5 & $2745.28951(58)^{d}$ \\
\hline 43 & 42 & $765.89402(-18)^{d}$ & 20 & 21 & $2349.23806(11)^{d}$ & 8 & 7 & $2962.13194(2)^{d}$ & 7 & 6 & $2761.07347(51)^{d}$ \\
\hline 44 & 43 & $776.44829(-5)^{d}$ & 19 & 20 & $2379.61531(-7)^{d}$ & 9 & 8 & $2977.56311(22)^{d}$ & 8 & 7 & $2776.21117(34)^{d}$ \\
\hline 45 & 44 & $786.57138(-48)^{d}$ & 18 & 19 & $2409.71011(-14)^{d}$ & 10 & 9 & $2992.30196(10)^{d}$ & 9 & 8 & $2790.69188(27)^{d}$ \\
\hline 46 & 45 & $796.26003(-167)^{d}$ & 17 & 18 & $2439.50654(-12)^{d}$ & 11 & 10 & $3006.33853(19)^{d}$ & 10 & 9 & $2804.50482(11)^{d}$ \\
\hline 47 & 46 & $805.51427(-83)^{d}$ & 16 & 17 & $2468.98849(-18)^{d}$ & 12 & 11 & $3019.66241(17)^{d}$ & 11 & 10 & $2817.64019(28)^{d}$ \\
\hline 48 & 47 & $814.32935(-21)^{d}$ & 15 & 16 & $2498.14010(-17)^{d}$ & 13 & 12 & $3032.26417(30)^{d}$ & 12 & 11 & $2830.08733(-5)^{d}$ \\
\hline & & & 14 & 15 & $2526.94524(-19)^{d}$ & 14 & 13 & $3044.13446(47)^{d}$ & 13 & 12 & $2841.83769(6)^{d}$ \\
\hline $\mathrm{v}=1$ & & & 13 & 14 & $2555.38789(-22)^{d}$ & 15 & 14 & $3055.26461(84)^{d}$ & 14 & 13 & $2852.88236(74)^{d}$ \\
\hline 11 & 10 & $229.36362(-31)^{d}$ & 12 & 13 & $2583.45204(-24)^{d}$ & 16 & 15 & $3065.64579(96)^{d}$ & 15 & 14 & $2863.21052(-14)^{d}$ \\
\hline 12 & 11 & $249.58956(25)^{d}$ & 11 & 12 & $2611.12169(-22)^{d}$ & 17 & 16 & $3075.26948(25)^{d}$ & 16 & 15 & $2872.81625(-24)^{d}$ \\
\hline 13 & 12 & $269.65344(-10)^{d}$ & 10 & 11 & $2638.38085(-19)^{d}$ & 18 & 17 & $3084.12987(37)^{d}$ & 17 & 16 & $2881.69100(-25)^{d}$ \\
\hline 14 & 13 & $289.54420(13)^{d}$ & 9 & 10 & $2665.21349(-24)^{d}$ & 19 & 18 & $3092.21897(36)^{d}$ & 18 & 17 & $2889.82721(-28)^{d}$ \\
\hline 15 & 14 & $309.24930(77)^{d}$ & 8 & 9 & $2691.60400(-15)^{d}$ & 20 & 19 & $3099.52994(-5)^{d}$ & 19 & 18 & $2897.21710(-110)^{d}$ \\
\hline 16 & 15 & $328.75519(41)^{d}$ & 7 & 8 & $2717.53624(-30)^{d}$ & 21 & 20 & $3106.05807(53)^{d}$ & 20 & 19 & $2903.85537(-138)$ \\
\hline 17 & 16 & $348.05158(66)^{d}$ & 6 & 7 & $2742.99505(-22)^{d}$ & 22 & 21 & $3111.79627(63)^{d}$ & 21 & 20 & $2909.73711(15)^{d}$ \\
\hline 18 & 17 & $367.12637(110)^{d}$ & 5 & 6 & $2767.96456(-26)^{d}$ & 23 & 22 & $3116.73981(69)^{d}$ & 22 & 21 & $2914.85236(-69)^{d}$ \\
\hline 20 & 19 & $404.56290(-22)^{d}$ & 4 & 5 & $2792.42963(-20)^{d}$ & 24 & 23 & $3120.88430(105)^{d}$ & & & \\
\hline 21 & 20 & $422.90385(-72)^{d}$ & 3 & 4 & $2816.37489(-22)^{d}$ & 25 & 24 & $3124.22514(132)^{d}$ & $\mathrm{v}=5$ & & \\
\hline 22 & 21 & $440.98016(6)^{d}$ & 2 & 3 & $2839.78537(-27)^{d}$ & 26 & 25 & $3126.75560(-143)^{d}$ & 6 & 7 & $2404.69448(-52)^{d}$ \\
\hline 23 & 22 & $458.77923(-17)^{d}$ & 1 & 2 & $2862.64640(-22)^{d}$ & 27 & 26 & $3128.48179(223)^{d}$ & 5 & 6 & $2427.13490(-50)^{d}$ \\
\hline 24 & 23 & $476.29204(-38)^{d}$ & 0 & 1 & $2884.94325(-20)^{d}$ & 28 & 27 & $3129.38973(121)^{d}$ & 4 & 5 & $2449.10492(-71)^{d}$ \\
\hline 25 & 24 & $493.50783(-159)^{d}$ & 1 & 0 & $2927.78725(-29)^{d}$ & 29 & 28 & $3129.48388(239)^{d}$ & 3 & 4 & $2470.59161(-10)^{d}$ \\
\hline 26 & 25 & $510.41955(-144)^{d}$ & 2 & 1 & $2948.30660(-29)^{d}$ & 30 & 29 & $3128.75719(72)^{d}$ & 2 & 3 & $2491.58076(95)^{d}$ \\
\hline 27 & 26 & $527.01780(-15)^{d}$ & 3 & 2 & $2968.20599(-30)^{d}$ & & & & 7 & 6 & $2671.17047(-11)^{d}$ \\
\hline 28 & 27 & $543.29197(41)^{d}$ & 4 & 3 & $2987.47230(-22)^{d}$ & $\mathrm{v}=3$ & & & 8 & 7 & $2685.82734(-37)^{d}$ \\
\hline 29 & 28 & $559.23278(-53)^{d}$ & 5 & 4 & $3006.09249(-19)^{d}$ & 13 & 14 & $2392.42100(-20)^{d}$ & $\begin{array}{l}0 \\
9\end{array}$ & 8 & $2699.83880(29)^{d}$ \\
\hline 30 & 29 & $574.83511(6)^{d}$ & 6 & 5 & $3024.05393(-27)^{d}$ & 12 & 13 & $2419.08144(-17)^{d}$ & 10 & 9 & $2713.19220(-33)^{d}$ \\
\hline 31 & 30 & $590.08899(5)^{d}$ & 7 & 6 & $3041.34460(-26)^{d}$ & 10 & 11 & $2471.24434(-36)^{d}$ & 12 & 11 & $2737.88914(-96)^{d}$ \\
\hline 32 & 31 & $604.98774(26)^{d}$ & 8 & 7 & $3057.95269(-13)^{d}$ & 9 & 10 & $2496.71661(-28)^{d}$ & 13 & 12 & $2749.21279(-172)$ \\
\hline 33 & 32 & $619.52346(-3)^{d}$ & 9 & 8 & $3073.86638(-23)^{d}$ & 8 & 9 & $2521.76281(20)^{d}$ & 14 & 13 & $2759.84325(-59)^{d}$ \\
\hline 34 & 33 & $633.69000(-12)^{d}$ & 10 & 9 & $3089.07498(-18)^{d}$ & 7 & 8 & $2546.36707(30)^{d}$ & 15 & 14 & $2769.76873(-73)^{d}$ \\
\hline 35 & 34 & $647.48108(23)^{d}$ & 11 & 10 & $3103.56756(-24)^{d}$ & 6 & 7 & $2570.51439(-1)^{d}$ & 16 & 15 & $2778.98156(-155)$ \\
\hline 36 & 35 & $660.88964(15)^{d}$ & 12 & 11 & $3117.33405(-23)^{d}$ & 5 & 6 & $2594.19124(62)^{d}$ & 17 & 16 & $2787.47534(-157)$ \\
\hline 37 & 36 & $673.91019(3)^{d}$ & 13 & 12 & $3130.36458(-19)^{d}$ & 4 & 5 & $2617.38038(-34)^{d}$ & 18 & 17 & $2795.24272(-67)^{d}$ \\
\hline 38 & 37 & $686.53704(-28)^{d}$ & 14 & 13 & $3142.64958(-31)^{d}$ & 3 & 4 & $2640.07035(26)^{d}$ & & & \\
\hline
\end{tabular}

${ }^{a}$ Observed-Calculated in parentheses.

${ }^{b}$ Ref. 27.

${ }^{c}$ Ref. 28.

${ }^{d}$ Ref. 3. 
Table S2 Values for $\omega_{\mathrm{e}}$ and $B_{\mathrm{e}}$ of DF and HF.

\begin{tabular}{ccc}
\hline Parameters & DF & HF \\
\hline & & \\
$\omega_{\mathrm{e}}\left(1+m_{\mathrm{e}} \Delta_{\omega}{ }^{\mathrm{F}} / M_{\mathrm{F}}\right) / \mathrm{cm}^{-1}$ & $3000.049020(527)^{a}$ & $4138.282951(727)$ \\
$B_{\mathrm{e}}\left(1+m_{\mathrm{e}} \Delta_{B}{ }^{\mathrm{F}} / M_{\mathrm{F}}\right) / \mathrm{cm}^{-1}$ & $11.009125342(566)$ & $20.94770637(108)$ \\
\hline
\end{tabular}

${ }^{a}$ The uncertainty (one standard error) in the last digit is given in parentheses. 